\title{
Representing the Unseen with "Our Journey": a Platform to Capture Affective Experiences and Support Emotional Awareness in University-Level Study
}

\author{
Tim Coughlan $^{1}$ (D) Kate Lister ${ }^{2} \cdot$ Mathijs Lucassen $^{2}$
}

Accepted: 9 June 2021 / Published online: 25 June 2021

(c) The Author(s) 2021

\begin{abstract}
Student mental health is a critical issue that institutions are struggling to tackle proactively. The wellbeing of students is largely invisible to institutions unless specific mental health conditions are diagnosed and disclosed. In comparison to the importance placed on academic aspects, the affective experiences of education throughout the study journeys of students are rarely acknowledged. Approaches for students to develop emotional awareness, through which they learn to understand and manage their emotions, are limited. In this article, we describe the design and evaluation of Our Journey, a platform for students to represent their study journeys through describing the events and emotions they experience. The conceptual and user experience design of the platform was derived from participatory activities with students and staff and has been further refined via several physical and online iterations. In this paper, we report findings from an exploratory pilot trial of Our Journey with 54 students studying for a range of qualifications at an online learning institution. Through an analysis of the journeys that the students produced and a post-trial survey, we found that Our Journey can support representations of emotional awareness in relation to study events which prompted students to reflect on important aspects of their study and personal development. The design and use of the platform have also prompted important considerations around how emotion is represented, as well as how the privacy and ownership of these representations of personal experiences can be managed to support students and institutions to potentially benefit from novel tools such as Our Journey.
\end{abstract}

Keywords Student experience $\cdot$ Mental health $\cdot$ Reflection $\cdot$ Evaluation $\cdot$ Online learning

\section{Introduction and Context}

Mental health is a critical issue in Higher Education, with an estimated one in five (Auerbach et al., 2016) and one in three (Lipson et al., 2018) university students experiencing issues related to their mental health. For instance, results

Tim Coughlan

tim.coughlan@open.ac.uk

Kate Lister

kate.lister@open.ac.uk

Mathijs Lucassen

mathijs.lucassen@open.ac.uk

1 Institute of Educational Technology, The Open University, Walton Hall, Milton Keynes, Kents Hill MK7 6AA, UK

2 Faculty of Wellbeing, Education and Language Studies, The Open University, Walton Hall, Milton Keynes, Kents Hill MK7 6AA, UK from the World Health Organization (WHO) World Mental Health Survey across 21 countries reported that $20.3 \%$ of students experience anxiety, depression and other issues to do with their mental health (Auerbach et al., 2016). In addition, many other students experience stress and adverse life events during their studies (Böke et al., 2019; Smyth et al., 2008).

There are a number of interventions which can support tertiary students with mental health problems, many of which follow established clinical approaches and show at least some evidence of effectiveness (see for example Cuijpers et al., 2016). However, interventions and university support, including those delivered online, tend to focus on reducing symptoms of mental ill-health (see for example Davies et al., 2014), rather than making sense of a student's affective experiences and/or attempting to understand the causes (or the antecedents) associated with mental ill-health (Markoulakis $\&$ Kirsh, 2013; Tinklin et al., 2005). Institutional concerns about students' mental ill-health can be very much visible 
and framed in alarming ways, such as when universities (and academics) talk of a "mental health crisis" on campus, frequently in fearful terms (Hawkes, 2019). This can lead to overly procedural responses to mental health problems (Wei, 2007), rather than investigative approaches to identify triggers and barriers in the system which can potentially lead to these problems.

In many ways, the day-to-day mental wellbeing of students remains invisible to many higher education institutions (HEIs), their pastoral focus is likely to be supporting students with disclosed mental health problems and those who are experiencing mental health crises. As a result, the focus is on emergency support and adjustments that are designed to support students to succeed (Hartrey et al., 2017). Arguably, there is too much recognition of the academic experience of students in higher education, and not enough of the affective experience, which is also applicable to every student's journey. Attendance to students' affective experiences in education has been argued to support deeper and more reflective learning and has been connected with greater levels of success (Boyle et al., 2007). For distance-based students, their affective journey is perhaps even more significant, as their experiences are less visible, and they do not have the same sort of opportunities for peer support, debriefs and validation, given they are not studying on a university campus with their peers (Barr, 2014).

O'Regan (2003) earlier argued that learning theories have largely drawn on traditional Western thought, which considers cognition and emotion as relative opposites which give primacy to cognition. While emotion is difficult to define, O'Regan (2003) highlighted the ways in which online learning could be influenced by experiences of frustration, anxiety, pride and enthusiasm. In more recent times the importance of emotion in learning is becoming increasingly recognised in educational technology research. For example, Petrovica et al. (2017) described how research on Intelligent Tutoring Systems, which aim to simulate human tutors by providing personalised content and feedback to students, has more recently considered the goal of developing Affective Tutoring Systems. These new systems seek to automatically recognise and respond to the student's emotional state, thus responding to an increased awareness that emotions affect student's motivation and ability to learn.

There is widespread interest in the field of educational technology related to the use of sensors to automatically detect student's emotions, for example, in deploying these in facial recognition through video or sensors which detect physiological changes. Depending on the approach taken, this could be costly or impractical to scale up. An alternative is to try to detect patterns in the individual's interactions with a system that indicates affective states without electronic sensors (Baker \& Ocumpaugh, 2015). These passive approaches also raise concerns related to privacy and how students may respond to knowing they are being analysed in such ways. This is probably unsurprising, as Pickard (2003) earlier suggested that "Emotions, perhaps more so than thoughts, are ultimately personal and private" (p. 61). While they defend the ethics of designing systems to automatically detect the emotions of users, Pickard (2003) also concedes that such systems could be used in ways that mislead or manipulate and could also lead to violations of privacy norms.

As an alternative, active approaches that prompt students to explicitly report and reflect on their own emotions give the student control over what they share and has the potential to support them to develop their emotional awareness during their studies. Educators should seek to support the emotional awareness of their students for a number of reasons, most notably in higher education because students do better academically when they can adequately understand and manage their emotions (MacCann et al., 2020). Encouraging university students to become more reflective and self-aware has its challenges because educators have long believed they must actively teach and/or model reflective skills in order to demystify reflective processes (Spalding \& Wilson, 2002). Consideration needs to be given to the support students need in order to reflect effectively. Ryan (2012) advocates for scaffolding around the reflection process; but Henriksen et al., problematise the tension between "learner autonomy" versus "instructional control" (Henriksen et al., 2018). Meanwhile, Hill et al. (2019) posit a pedagogic partnership as a suitable approach to maintain balance, where students explore their affective experiences whilst also learning in partnership with, and supported by, faculty members, while Stork (2020) suggests a "digital storytelling" approach. But irrespective of whether a student is formally taught to reflect or is supported to reflect, the demand for this remains, as Veine et al. (2020) have previously highlighted: "In practice, students will face several situations that are unclear, confusing, complex, and unstable; the outcome may be highly uncertain, and the goals may be conflicting. Such situations demand a reflective approach" (p. 148).

This approach can be encouraged through reflection journals (also referred to as reflective diaries or learning logs). These are a commonly used tool to promote a reflective approach whereby students write down events they have experienced, what it meant for them and what they might have learned from the experience (Veine et al., 2020). The student's journal (or similar tool) acts as a "container" for writing, thereby providing students with the framework needed to structure and remember their thoughts and reflections (Veine et al., 2020). These reflection journals are used more frequently in certain subject areas, such as in placement-orientated professional programmes including nursing and teacher education, and 
considerably less so in subject areas such as engineering (Wallin \& Adawi, 2018). Furthermore, aside from the educator who checks or marks this journal as part of an assessment, the student's experience as documented in a reflection journal remains invisible to other students, staff and the institution more widely.

The initial goal for the development of Our Journey was to create a means for students to represent their individual study journeys - the sequence of events they experienced which were related to, or impacted on, their study experience. This was intended to support students and staff to communicate and reflect on these experiences together. Earlier participatory research with disabled students uncovered a lack of appropriate means to represent the important events in their study experiences and how these unfold over time to impact on the individual. As we explored this area further with students, it became clear that there was potential to address this issue in a way that benefited all students, not only those with disabilities. Institutions often create visual representations of "the student journey" which assume that all students follow the same linear series of functional activities required to complete a course. Instead, we aimed to create a structure for shared artefacts that could capture and communicate individual lived experiences of study (Coughlan et al., 2019).

Our Journey is an accessible online tool that can be used to support students in developing their emotional awareness whilst also encouraging student reflection. Moreover, Our Journey can record data about students' affective experiences in a structured form and at scale. potentially offering HEIs a valuable opportunity to learn about their students' affective experiences in higher education. In this exploratory, pragmatic pilot study, we have trialled Our Journey with non-traditional participants, specifically mature students in a distance learning environment. However, the design is flexible such that it could be readily adopted in conventional face-to-face or blended education settings.

The primary objective of this study was to conduct a naturalistic exploration of students' affective experiences using Our Journey. A secondary objective was to elicit from the students ways in which they felt the platform needed to be further refined for future use. The research questions we aimed to answer through this were:

1. In what ways can a representation of a study journey, created by a student, support greater understanding of the affective dimension of their study experiences?

2. What areas of study and experience does this prompt students to consider and reflect on?

3. What responses do students have to the Our Journey platform and the ways that it could be used by them individually and potentially by staff or others?

\section{Development of Our Journey}

The concept of Our Journey was initially developed through a series of participatory research and design activities. The first stage of this was a participatory research initiative which explored the experiences of members of the Disabled Students Group at our institution to identify priority areas for research and action which was likely to be of benefit to them. One of the conclusions from this initiative was the lack of effective means - for disabled students in particular - to communicate the barriers and challenges they faced to staff at the institution (Coughlan et al., 2019).

Inspired by this, we aimed to develop an accessible and extensible means to represent student journeys. Additional participatory research and design activities with students, staff, and sector stakeholders (including charities and organisations supporting disabled students) informed the graphic design work which led to the creation of the core features of Our Journey. In particular, the "board game" look and feel which included "cards" that could be added to a "board", each containing an event type, emotion and associated description.

Rather than being driven by a pre-existing theoretical framework, the solution proposed was based on principles and key features that were derived from the co-design activities. These were that Our Journey:

- Should be engaging, such that students would feel motivated to use the tool and it did not feel like a standard study activity or assignment;

- Should be able to represent a student's achievements and goals as well as the challenges;

- Should include a range of events in a student's life, including those unrelated to their studies; and,

- Should not have a set starting point (e.g. registration), but rather would allow the student to decide the scope of their journey and the events that they felt were important to include.

Our Journey was initially developed as a physical set of cards and a large accompanying board for use in co-located, in-person workshop-type activities and discussions. Figures 1 and 2 show the card design and use of this in a workshop. A prototype online version was then created and used in various activities, most notably as an optional activity in foundation level "Access" courses in which students were asked to create their journey as a means of reflecting on their early experiences of study, how they had previously responded to any challenges and/or set themselves goals.

Further workshops and evaluation of early versions of Our Journey with students have informed the iterative 


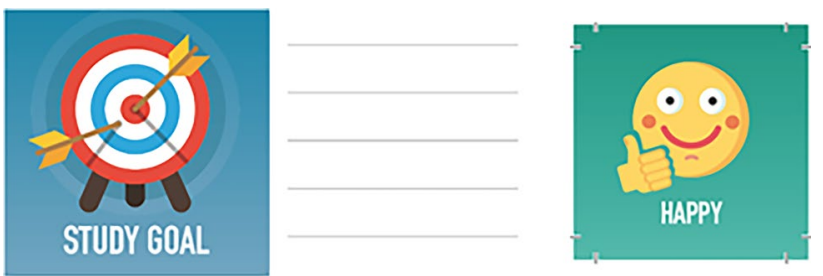

Fig. 1 A rectangular "event card" with an icon on the left showing an archery target and arrows hitting it with the title "study goal" and space for a text description on the right. Next to this, a smaller square card with a smiling emoticon showing a thumbs up and the title "happy"

development of a fully functional online platform for students to create, save and return to their journeys. The student-facing interface for this is shown in Figs. 3 and 4. There have been refinements to the categories of events that students are provided with, and the emotions that can be linked to these. In the trial described in this present paper, the types of events and emotions were drawn from written narratives of student journeys and then refined and added to via feedback in workshops and use with students. As a result, the emotions (and associated terminology) that could be represented in Our Journey were devised based on student input, rather than specific theories or frameworks related to human affect or emotion.

The platform was devised to be flexible in order to extend its usefulness and foci, meaning that students (and potentially staff) can explore areas and themes in the student journey that are of interest to them. The representation of emotions in relation to each event foregrounds the affective dimension of study journeys in the graphical and interaction design. This supports the focus on the representation, reflection and self-awareness of emotional wellbeing in this paper. Other foci for Our Journey activities, such as using it as a tool to structure and reflect on personal or professional development, also appear fruitful but are beyond the scope of this paper.

In order to support use by institutions, courses, personal tutor groups or other groupings of students, we created functionality for "Groups" and "Hosts". Students are invited to join groups, which are managed by hosts, who also can access a student's journey if the student consents to this being shared.

The platform is independent of any specific institution and does not require linking to the account that the student holds with their institution. This means that the student could keep their journey and continue to use the platform after leaving one institution to transition to another. An email address is required to sign up, but users do not have to identify themselves with their full name or provide an institutional affiliation. They can join or leave groups at any time, therefore controlling how their data is shared with particular hosts, courses or institutions. In this trial, we gained consent to analyse the journey data provided by participants in conjunction with records about them held by the university. This process could be integrated into the platform with further authentication if deemed appropriate, but it was done manually in this case to support this research project.
Fig. 2 A table at which a group of people are building a journey on a large poster using numerous cards as described in Fig. 1

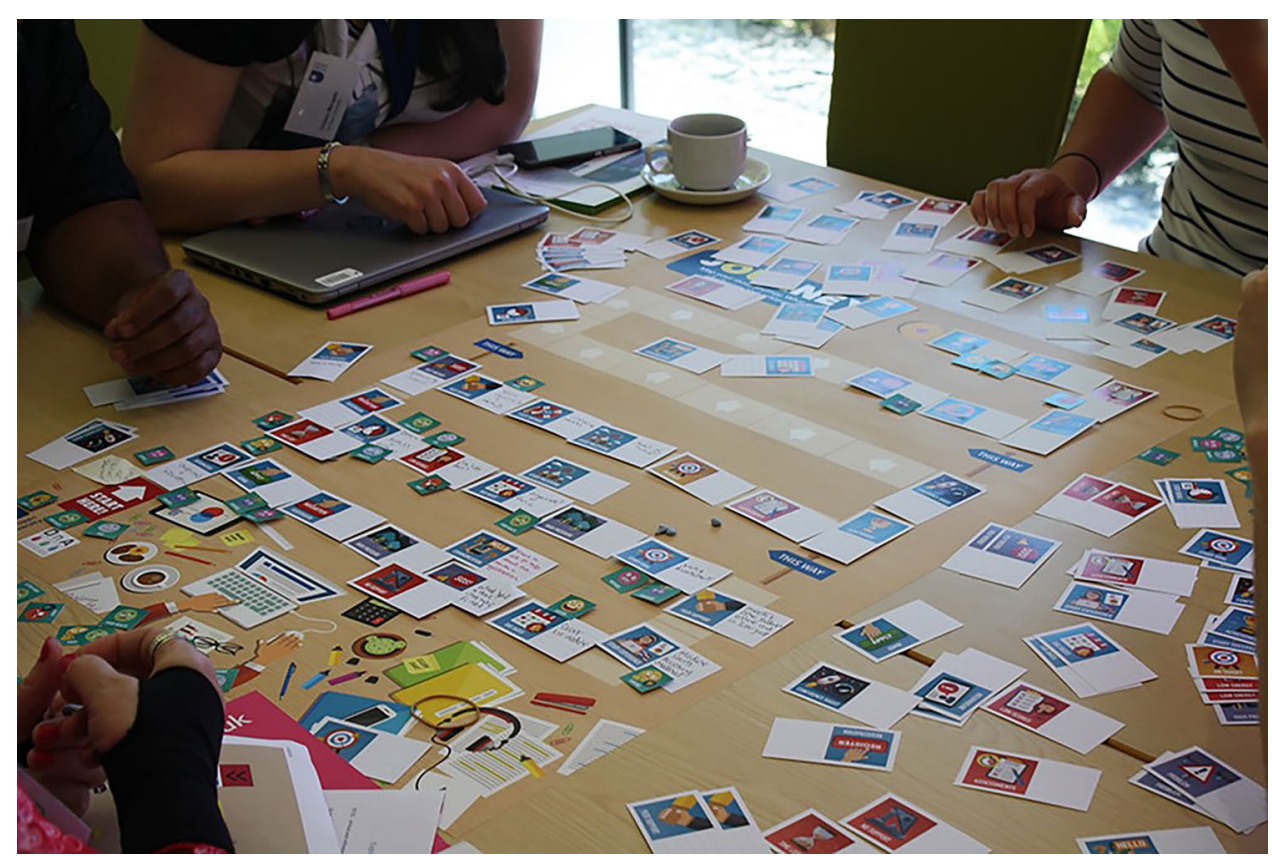




\section{A. N. Other, tell us about your journey}

\author{
What happened? \\ Select a word or \\ an event \\ connected to your \\ journey:
}
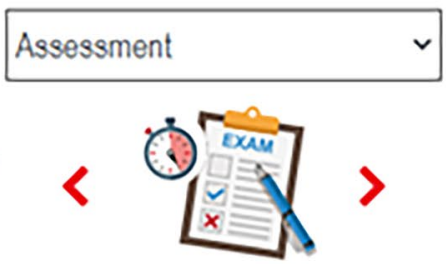

\section{Describe the event (optional)}

The exam is coming up but I feel like I understand the material this time.

126 characters remaining
How did you

feel?

Select a word or emoji which describes how you felt:
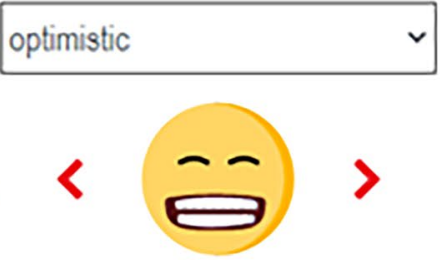

When did it happen? (optional)

25 June 2020

Add any word or date format you like. For example: 25 Junc 2020 | June 2020 | Summer $2020|2020| 2019$
Fig. 3 An interface titled "A. N. Other, tell us about your journey" with four areas for input: "what happened?" with a drop down menu currently on the event type "assessment"; "describe the event (optional)" with a text box currently reading "The exam is coming up but I feel like I understand the material this time"; "how do you

\section{Study Methodology}

Our aim in the current study was to trial Our Journey with a diverse group of students, producing a set of affective "journeys" created by the participants, whilst also capturing their feedback about the platform and their experience of using it through a survey. The study was approved by the Human Research Ethics Committee (HREC) of The Open University.

\section{Initial Testing}

To assess that Our Journey could be used independently by students and to identify usability issues or areas of confusion to address, four students were recruited for initial testing in which they were asked to follow the instructions developed for the main trial, create a journey, and complete the survey. Afterwards, the participants were interviewed to discuss any issues they encountered. Minor improvements were made to the tool as a result prior to the beginning of the pilot trial, but it was concluded that the tool was ready for independent use and the instructions were sufficiently clear. Of note, these initial test participants did not take part in the main pilot trial. feel?" with a drop down menu currently showing "optimistic" and the related emoji for optimistic also displayed; and "when did it happen?" (optional) with date 25 June 2020 input into a text box. At the bottom a large "add" button to complete the creation of the card

\section{Recruitment}

An email advertising the trial was sent out to a randomly selected sample of students enrolled across five undergraduate qualifications, which were chosen to provide a diverse range of subjects across the university's faculties (Business Management, Health and Social Care, Law, the "Open Degree" and Natural Sciences). In order to avoid having participants with no history of study at university-level to report upon, the sample only included students who had already taken at least one undergraduate module. The advertisement was emailed to 2000 students in total, split into 400 students from each of the five qualifications. As part of the post-pilot survey, participants could enter a draw to win one of ten gift vouchers.

\section{Pilot Trial Procedure}

After being provided with information about the study and asked for their written consent to take part, the participants were asked to view instructions including an introductory video (see: https://iet-ou.github.io/our-journey/video-new. $\mathrm{html}$ ) which showed a student representing their "journey" using the platform. They were then guided to $\log$ in and set 


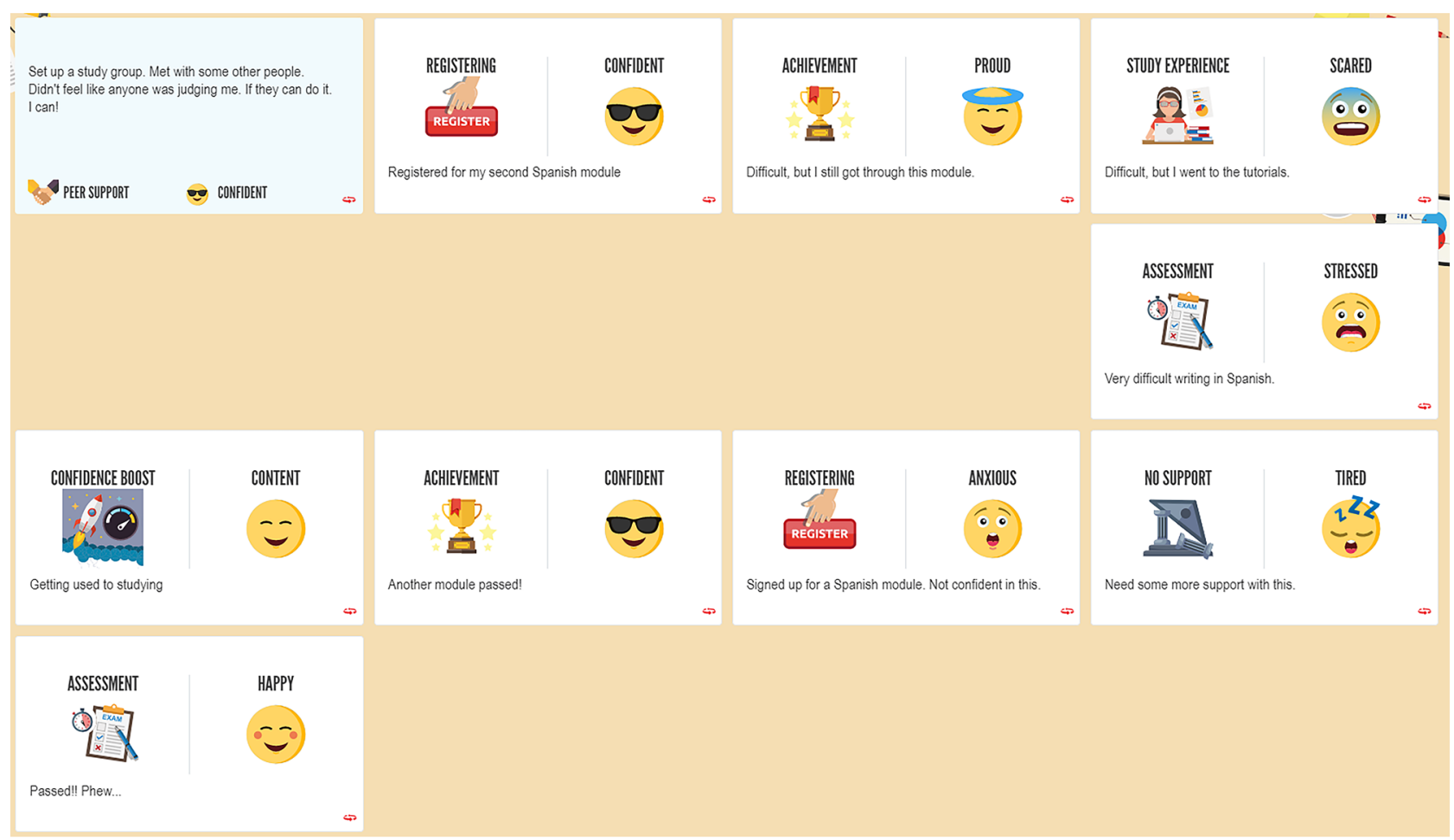

Fig. 4 A series of cards as shown in a student's journey. The cards are shown in a line crossing back and forth on the web page and making an "s" shape like a snake

a password, asked to explore the platform and when ready to begin creating their journey. The guidance on this task was to:

"Post the cards you create to tell the story of your own student journey. The amount of detail you provide is up to you. Take as much time over this activity as you want to"

"Start by thinking about the events that you feel represents the beginning of your journey to becoming a student. Try to include all the events after that that you feel were important".

A notable feature of the pilot trial task was that students were asked to report a retrospective journey of events they had experienced to date. Essentially, this meant that they were creating a narrative based on past events as a one-off activity, rather than continually reporting events by using the platform in a longitudinal way. Both of these models of use have the potential to prompt discussion and reflection around experiences and wellbeing, but this trial only really explored the potential of Our Journey as an activity undertaken at a single point in time. However, the participants were informed that they could leave and return to their journey at any time and that their input would be saved.

The participants were told that their data would be analysed in conjunction with information from their student records, but that all reporting of the information they provided in their journey would be anonymous. The participants consented to share personally identifiable versions of their journeys with the research team.

\section{Survey}

Approximately 1 month after they had responded to take part in the study, all the participants who were identified as having logged in to Our Journey were sent a link to the study's survey. The survey included open and closed questions about their experiences related to the trial task, the aspects of their journey it encouraged them to reflect on, the design and usability of the platform and their views on if and how they would like to share their journeys. Questions and results are described in the "Survey Results" section.

\section{Findings}

Fifty-four participants took part in the trial by responding to the advertisement email, logging in and creating at least one event card in Our Journey. In total, 41 were female and 13 were male. Although there is a majority of female students in the university, this ratio is greater amongst the trial participants, with $26 \%$ male, compared to $38 \%$ in the overall undergraduate population (Open University, 2020). 
The most common age groups were 26-35 years old (22 participants) and 36-45 years old (12 participants). The university offers a flexible approach to study to serve part time and lifelong learners with many studying alongside work, and these two age groups are also the most prominent in the overall student population (Open University, 2020). Fortynine participants disclosed their ethnicity as white, three as black, one as mixed and one participant refused to provide this information. Nine participants had declared a disability. With regard to ethnicity and disability these proportions are similar to those of the whole university population (Open University, 2020).

Of the participants, 34 created more than five event cards and 20 created more than 10 event cards, with an overall mean of 9.72 cards per participating student. The platform offered 29 types of event that participants could select from to describe each card they created. The five most frequently used types of event in the cards created in this trial were the following: "Study experience" $(n=71)$, "Registering" $(n=64)$, "Assessment" $(n=47)$, "Results" $(n=45)$ and "Considering study" $(\mathrm{n}=34)$. All other events were used at least three times, the exception being "Repetition" which was not used. Thirty-six of these participants completed the survey.

\section{Illustrative "Journey" Examples}

Below are five examples of student stories that are illustrative of the affective experiences and/or the emotional awareness students demonstrated in relation to their journeys. All names are pseudonyms, and selected demographic details have been omitted to protect the anonymity of the participants.

Maria is female, about 46-55 years old and of mixed ethnicity. She has a child and is studying for a BA in Law. When she started her studies, she "had no clue about how to start studying and felt totally overwhelmed", but "managed to complete the year with an ok mark". In her second year she started home-schooling her son and says she was

APRIL 2019

Having to study rape after being sexually assaulted was probably my most difficult time at Was 10 weeks of hell that I just had to get through. I I worked so hard $90 \%$ but was very painful.

\section{N. MILESTONE}

Fig. 5 Card with description "Having to study rape after being sexually assaulted was probably my most difficult time at the [university]. Was 10 weeks of hell that I just had to get through. I worked so hard $90 \%$ but was very painful." Emotion "scared", event type "milestone" "feeling very unqualified to study, trying to juggle homelife and work. Not really ever feeling on top of things." She recounts a few difficulties that year, such as writing an essay which "I thought was ok but failed very miserably' and of having a "Very ineffective tutor". However, her chief difficulty appeared to be about studying a triggering subject (see Fig. 5). She wrote:

"Having to study rape after being sexually assaulted was probably my most difficult time at the [university]. Was 10 weeks of hell that I just had to get through. I worked so hard $90 \%$ but was very painful."

She then went on to outline how she dealt with this challenge:

"Didn't want to study rape alone. Brought it up in a tutorial and many females were grateful I had done so."

"Met a fellow student called [named removed] and we got on and sometimes we would phone each other and we met a few times before the summer exams and revised together this was so great."

Finally, Maria "got $87 \%$ in my end of year two exams" and concluded, "I worked very hard and could not have done more. Law does not come easily to me at all. I am not logical but disorganised". She also "felt [the university] had been thoughtless and underestimated how many females had been assaulted".

Sarah is female, white and under 25 years old. She works part time and originally signed up for a degree in Classics, which she changed partway through her studies to an Open Degree (a flexible qualification where she could choose modules in different subjects). She has dyspraxia, which impacts on her studies, particularly in relation to assessments. She stated:

“Being Dyspraxic isn't easy. I was unsure that I had really understood the questions in the assignment.

Every time I felt disappointed by more score and felt

that the course wasn't accessible to me."

She passed her first module but did not enjoy it. She wanted to change direction but "Couldn't work out how to change courses so took a smaller module due to changes at work". She had difficulties with confidence and understanding her marks; she "struggled to know where I had gone wrong but was too afraid to ask". Things seemed to come to a head when she "Became pregnant. Struggled to process things. Dyspraxia kicked in more. Managed to mentally blank $1 / 3$ of the Economics paper so scored badly on the assignment. Hated myself for a few months". This was clearly a challenging time, and she became "afraid of messing up this exam like the last one". However, "It didn't happen and I felt a lot better for it, knowing that if I worked harder than normal, I had a chance of passing the module". 
Finally, she took "some time off work which allowed me to focus on my final assignment. Still working on it but have almost completed it and am hopeful that I can pass the module and move on".

Carol is a white female, about 26-35 years old and working full time in retail but wanting a career change. She made the decision to do a science degree and wrote about getting the "major boost that I needed" when she received her first course-related materials in the post. Part way into the course, she got her "dream job", so she took a study break while she adjusted to the new role. She describes returning to study as "different to what I had experienced previously, it was all online, no face to face tutorials and no books. This was rather difficult for me to adjust to". She then became pregnant; "Exam time with morning sickness, not a good mix. I was so worried I was going to have to run out and ruin my exam, but it held off and I passed". However, once her baby was born, she struggled even more:

"Having my first child, I never knew what being tired meant. But I had a very understanding tutor who gave me tips on how to fit in study as well as being a mum."

She progressed "despite feeling sleep deprived" and is now "registering for 60 credit course, returning to work and looking after toddler, AH!!".

Paul is male, over 56 years old and registered for a science degree. He did not disclose his ethnicity or employment status but stated, 'after 30 years of poor academic achievement and bad health, I was finally correctly diagnosed and my health improved. I started thinking "Lets see if I can do a degree" He describes in detail his early days of preparing for study, setting up a study space in the garage and choosing his modules and qualification. However, when he started, he says "I didn't really have a study plan and was constantly behind in my studies". He notes that he is only able to complete assessments "if I waited until 5 days before they were due" (see Fig. 6). He says he had "trouble seeking

[LEVEL 1] OCT 14 - JUN 15
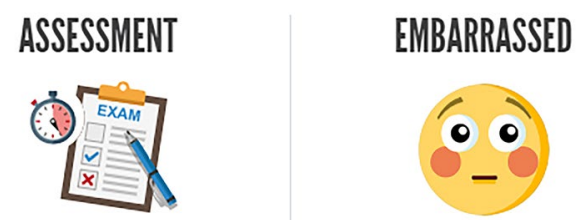

Problem starting assessments. Could only do them if I waited until 5 days before they were due ( and learnt...

Fig. 6 Card with description "Problem starting assessments. Could only do them if I waited until 5 days before they were due..." Emotion "embarrassed", event type: "assessment" help and mixing with people" but that he did "really enjoy" the tutorials because "It helped reassure me that everyone was having trouble, not just me". As he progressed in his studies, he "continued to have problems studying and starting assignments but always managed to complete them and get reasonable marks" and he "felt bad about my lack of organisational skills". However, he passed the first year and as he progressed, he 'accepted that (starting assignments close to deadlines) was my "Normal". Throughout the second year, he had "problems reading course work and starting assessments. But I'm not so worried about it now as I know that's my normal way of studying".

Paul passed the second year but encountered difficulties with practical projects. He reported "The first project involved categorizing Snails. I put a LOT of effort into finding snails but couldn't. Really dented my confidence”. The next project involved studying bird feeding habits and for this Paul "built a bird house with built in cameras" but recognised that he "spent so much time on over thinking the projects that I realized that I was in danger of not catching up with the course material". However, it also led to a revelation: "I realized something was different about the way I think-nothing was easy and never had been. On my 58th Birthday I was finally diagnosed with ADHD [Attention Deficit Hyperactivity Disorder]. Finally everything makes sense!" Recognising the difference this could make, he "deferred the module to give myself time to adjust to my new medication". He later registered to continue his studies, saying "Now that I know how my brain works, and I'm on medication to slow it down, I feel confident that my [university] experience will be a much more rewarding this year".

Elizabeth is a white female, about 26-35 years old and enrolled in a degree in Health and Social Care. She disclosed a mental health condition to the university, and recounts some of the ways in which her studies and her learning impacted upon her. When starting her degree, she commented that "I suffer from anxiety and impending due dates started to fill me with absolute dread!" After her first module, she "had a dramatic change in personal circumstances, becoming a single parent to my two children due to marital breakdown". She took a break from studies at this point, and talked about how helpful the student support team were when she returned to study; "When I felt ready to return to my studies the student support team helped me to get back on track." Similarly, she found her tutor extremely helpful when she had issues with mental health later in her studies; "my mental health took a bit of a knock and I suddenly became very anxious. I emailed my tutor who was a HUGE support and checked in on $\mathrm{m}(\mathrm{e})$ regularly after." This support was clearly beneficial to her studies and her confidence; she commented that passing level 2 of her degree course that "Finally I could see my hard work coming together and I became hopeful that I might actually do well!”. 


\section{Survey Results}

Thirty-six students completed the survey, which comprised Likert-type scale questions (strongly agree to strongly disagree) and questions requiring an open text response. Most respondents $(83.4 \%)$ agreed or strongly agreed that they enjoyed reflecting back on their study journey. A majority of respondents $(68.6 \%)$ also reported that they did not find it hard to create their journey. Several students specifically cited the benefits of Our Journey in terms of it supporting reflection in their free-text feedback in the survey's comment boxes. Recurring points included encouraging wellbeing by reflecting on achievements: e.g. "It helped me realise how much I've accomplished. Studying can be tedious and at many times feels like it's going nowhere but this helped me realise I've done so much! It made me proud and gave me the strength to continue.", and that emotional awareness could be developed through reflection on the past. For example "It helped to put things in perspective - I was hoping to gain a first but I don't" [think this is] "possible now, however, it reminded me that I've achieved a lot so far... I hadn't believed that I was capable of university level education. This helped to relieve some stress."

However, the participants also identified areas for improvement. These included the limits currently imposed in the platform design: "Very limited in terms of types of choices to reflect on, ability to write comments. Introduce some more freedom". The other issue identified pertained to the suggestion that journeys could be shared with other students: "I think the purpose of the journey is for self-reflection, which can be hindered if you believe that at some point someone else will read it. It could be disheartening to read other students' journeys, as it's another form of comparison which ultimately is probably not that useful."

Students reported that Our Journey prompted them to think about: the difficulties they have faced $(94.3 \%$ of respondents agreed or strongly agreed), their study achievements $(91.4 \%)$, their goals $(77.1 \%)$, the skills they developed or demonstrated through their studies $(74.2 \%)$, how they respond to difficulties (69.4\% of respondents), their mental wellbeing $(65.7 \%)$, their approach to studying $(65.7 \%$ of respondents), what they want to do next (62.9\%), how to complete their qualification ( $57.2 \%$ of respondents), their time management (54.3\%) and how they communicate with others in relation to their studies $(54.3 \%)$. However, free-text feedback from several students suggested that the limitations at present, for example in relation to the events and/or emotions/emojis presented, restricted their engagement and what they represent in terms of their student experience. For instance, students commented "Add more emotions and feelings", "You couldn't add your own event (types) and I wish you could write more in the text box. Also, more emotions for the how did you feel part" and "I would have preferred there to be slightly more options from the emotions drop down menu. Sometimes it was hard to assign the proper event—for example, study progress, achievement or success."

When asked how long they had spent creating their journey in the trial, most participants reported spending either $30 \mathrm{~min}$ to $1 \mathrm{~h}(38.9 \%)$ or between 1 and $2 \mathrm{~h}(25 \%)$ on the activity. When asked if and when they would like to return to update their journeys, the majority suggested "during or after every module" (55.6\%) and the second most popular option was "monthly" (19.4\%). Only two respondents (5.6\%) stated that they never wanted to update their journey.

Almost three-quarters of respondents $(71.4 \%)$ would like to see Our Journey being used to provide feedback to the university about their experiences as a student. Students were supportive of certain staff having access to their whole journey, specifically the academics who created their modules and qualifications (72.3\%), staff from student support services $(71.5 \%)$ and their tutors $(62.8 \%)$. Few students wanted their whole journey to be made available to the general public (8.6\%), to the people they are connected with on social media (14.3\%), "all staff and students" at the university $(20 \%)$ or their family and friends $(22.8 \%)$.

\section{Further Development Following the Trial Evaluation}

\section{Emotion Representation}

Feedback from the trial suggested that the available emotions tended to be quite "intense" and students would prefer to also have "milder" emotions to choose from. Therefore, in the revised version, emotions were organised into six scales, each consisting of six emotions ranging from strongly negative through to strongly positive (see Table 1).

Hosts can also access a heatmap which provides an overview of how event types correspond with emotions for their groups. Because of the new scale's approach, this can be amalgamated to present a simplified view of all emotions on the scale from very positive to very negative (see Fig. 7).

\section{Suggested Experiences}

As part of the group experience, hosts are now able to suggest events that their students might like to add to their journey (i.e. if the host would like feedback on a particular shared event, such as a placement, careers fair or university social event). These appear as a notification and a set event, and the student is invited to customise them with an emotion and accompanying text and add them to their journey (see Fig. 8). The student is able to ignore or dismiss the suggested experience. 
Table 1 Scales and ranges of emotions implemented in the post-trial version of $\mathrm{Our}$ Journey

\begin{tabular}{llllll}
\hline Very negative & Negative & Mildly negative & Mildly positive & Positive & Very positive \\
\hline Despair & Confused & Disappointed & Thoughtful & Optimistic & Confident \\
Upset & Stressed & Unhappy & Content & Happy & Excited \\
Scared & Anxious & Nervous & Reassured & Relaxed & Inspired \\
Angry & Frustrated & Concerned & Grateful & Determined & Motivated \\
Unwell & Tired & Bored & Relieved & Surprised & Enthusiastic \\
Guilty & Embarrassed & Self-conscious & Pleased & Satisfied & Proud \\
\hline
\end{tabular}

\section{Discussion}

In what ways can a representation of a study journey, created by a student, support greater understanding of the affective dimension of their study experiences?

Analysis of the journey data from this trial shows that the platform can capture important events that help to explain wellbeing issues, but are not stored on university systems or visible through learning analytics. In Fig. 10, the journey cards show important details of affective experience that could aid understanding of student data that is already held by the institution.
In this case, the student passed the module they are discussing, so there would not be a concern based on their record. However, they later withdrew from some subsequent modules and the journey data helps to understand this.

The journey data also captures experiences that are ongoing (i.e. concerns over lack of study skills), cumulative (i.e. anxiety around assessment) or beyond a module-level data point (i.e. a major life event, such as having a baby or changing job, taking place in a break between modules).

The data from this pilot trial also allows us to explore what might be possible in identifying patterns in affective

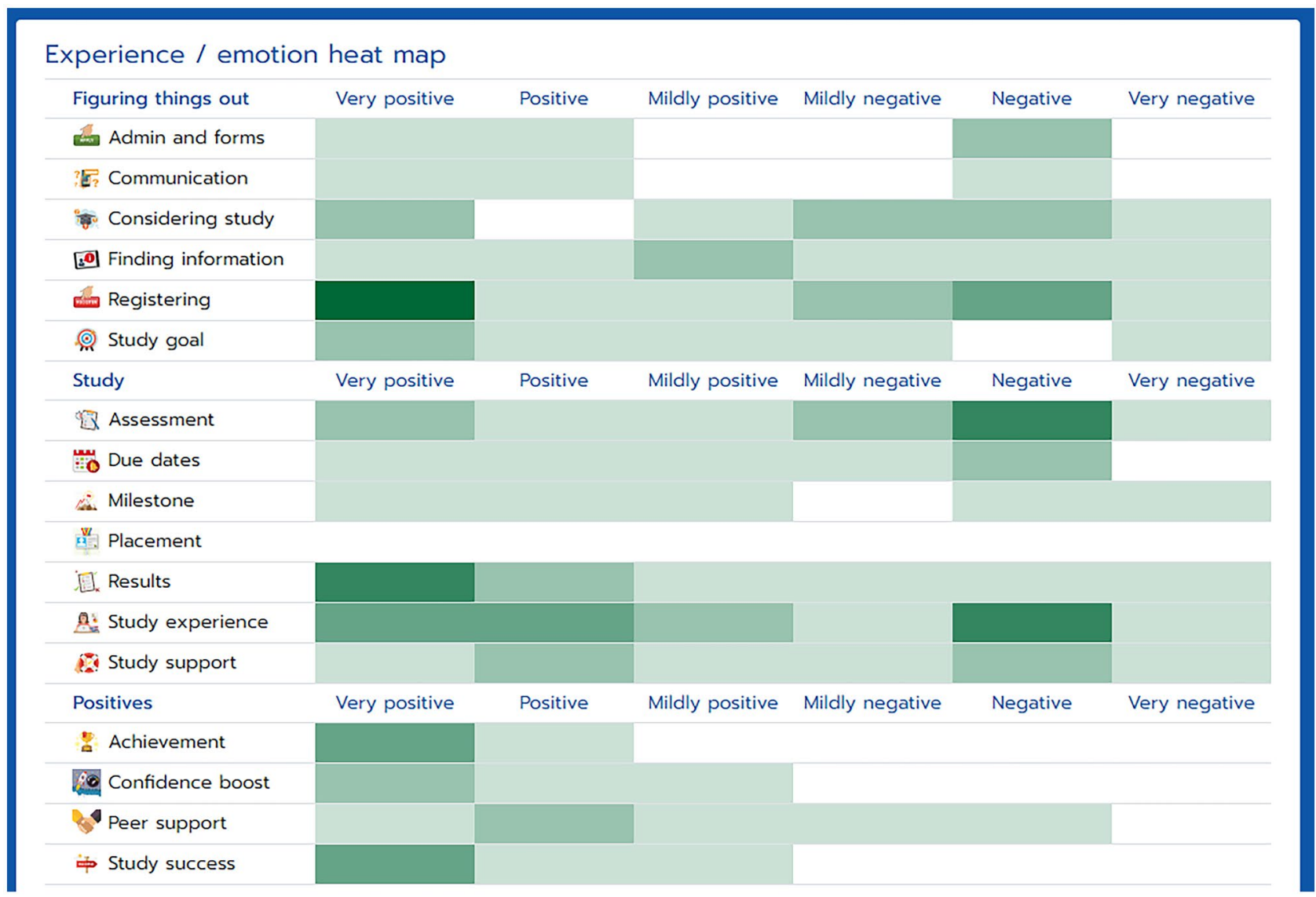

Fig. 7 Experience/emotion heat map showing each event type and the spread of responses given in cards according to whether emotions selected were "Very positive", "Positive", "Mildly positive", "Mildly negative", "Negative", and "Very negative" 


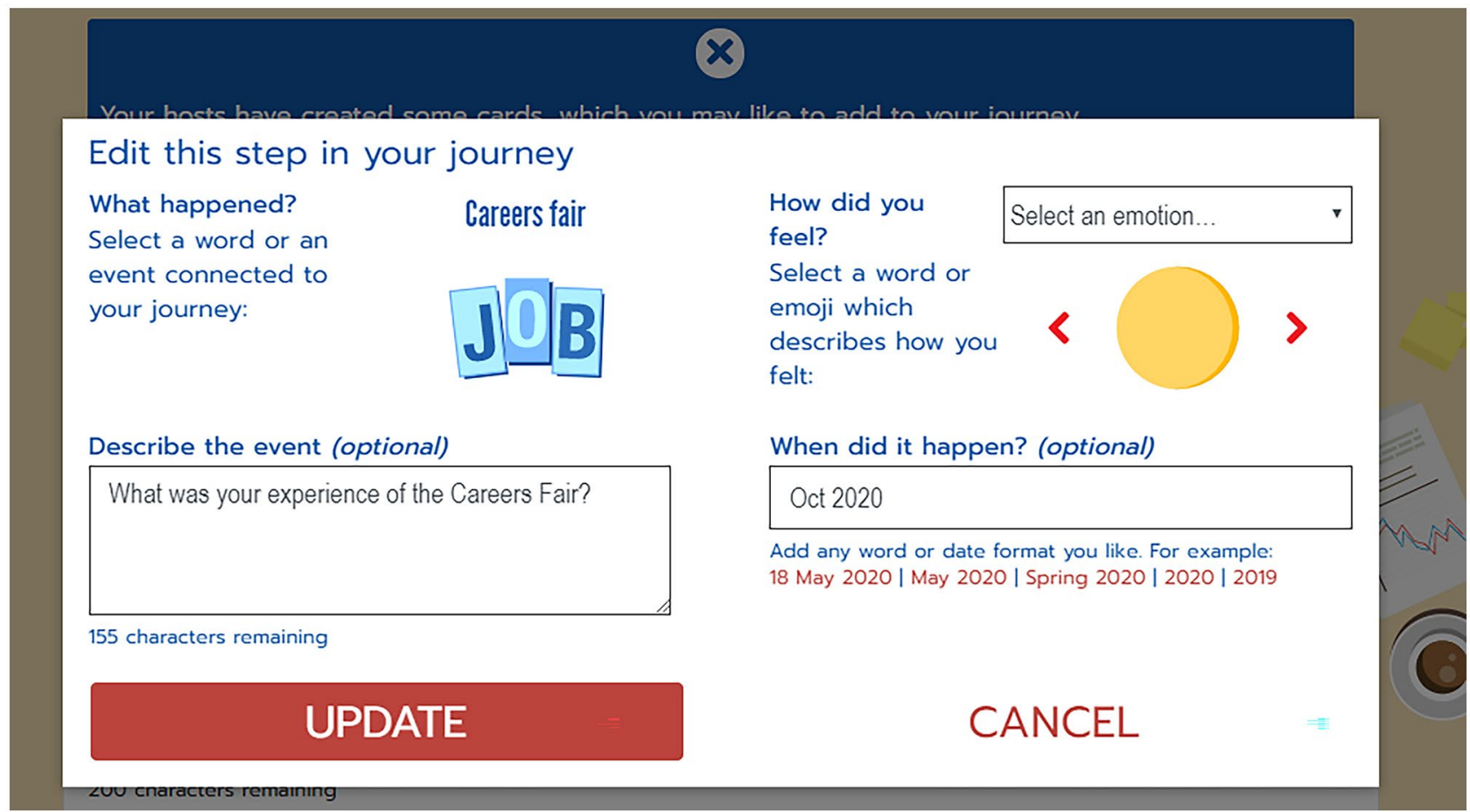

Fig. 8 Interface as shown in Fig. 3 but with suggested experience "Careers fair"

experience, in terms of emotional responses to events and how students make sense of these. Common combinations of emotions and experiences/events can be identified across the data (Fig. 9). For instance, assessments were most commonly linked to "negative emotions", such as an anxious, nervous or stressed state, whilst "results" were frequently linked to "positive emotions" such as feeling proud and happy. This is logical, given that students commonly feel anxious during assessments, and results if they are the "hoped for" grade will produce a positive emotional response. However, the ability for the student to reflect on their affective experiences and make sense of them may be able to add value in terms of supporting students in terms of their learner journey.

There is value in capturing students' affective experience so that student can make sense of their emotional wellbeing as it relates to their challenges and study experiences. In addition to how they combine their studies with other aspects of their lives.

One of the constraints in the trial was that the types of events captured in the structured data are of a fairly high level, e.g. a generic "study experience" rather than a more specific type of event. This is part of the rationale for the new functionality for host-generated events, and so these may be key to

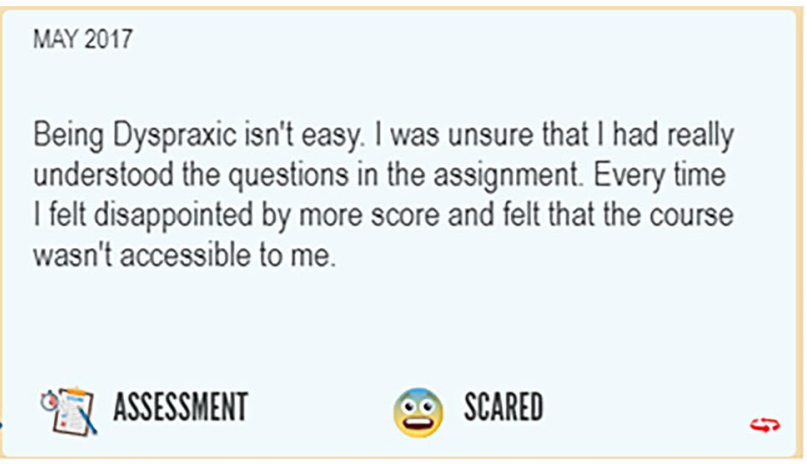

NOVEMBER 2017

Some results were lower that expected but they summed up the study experience. I didn't feel supported by my tutor and struggled to know where I had gone wrong but was too afraid to ask.

\section{R: STUDY EXPERIENCE}

\section{ANXIOUS}

$\Leftrightarrow$

Fig. 9 Part of heatmap as shown in Fig. 7 showing how "Assessment" events are more commonly connected with negative emotions, whereas all "Results" events are linked with positive emotions 


\begin{tabular}{|c|c|c|c|c|c|c|}
\hline Study & Very positive & Positive & Mildly positive & Mildly negative & Negative & Very negative \\
\hline \multicolumn{7}{|l|}{ Assessment } \\
\hline \multicolumn{7}{|l|}{ 监 Due dates } \\
\hline \multicolumn{7}{|l|}{ Milestone } \\
\hline \multicolumn{7}{|l|}{ Q". Placement } \\
\hline D. Results & & & & & & \\
\hline
\end{tabular}

Fig. 10 Two event cards. First describes that "Being Dyspraxic isn't easy. I was unsure that I had really understood the questions in the assignment. Every time I felt disappointed by more score and felt that the course wasn't accessible to me" Event type is "assessment" and emotion type is "scared". Second describes how "Some results

understanding more about emotional responses to events and to linking other analytics data with the emotional responses.

What areas of study and experience does this prompt students to consider and reflect on?

The survey results identify that individuals found that the activity of creating journeys prompted them to think about important areas, such as how they responded to difficulties, skills they developed or demonstrated through their studies and their mental wellbeing. These, combined with comments from individual journeys, broadly indicate demonstration of emotional awareness (Boyle et al., 2007).

The survey findings also indicate that the platform was easy and enjoyable to use for the majority of students. This may be because the reflection activity is inherently scaffolded (Ryan, 2012) within the tool, and that expectations, in terms of character limits, are clearly set (Ryan, 2012). Furthermore, the tool offers opportunities for pedagogic partnership and support (Hill et al., 2019), as it can facilitate shared reflection and dialogue.

What responses do students have to the Our Journey platform and the ways that it could be used by them individually, and potentially by staff or others?

Our findings both from this trial and from workshops with students suggest care is needed around sharing the platform and sufficiently maintaining privacy. Affective experiences might be unseen because they can be deeply personal or private. Stigma can be a powerful factor in this; Martin (2010) found that many students preferred to keep their mental health to themselves out of fear of judgment or discrimination, and Gulliver et al. (2019) found that the factors that influence whether a student chooses to speak to university staff, and who they approach, are extremely complex. Our Journey may have potential to help with this; Jamissen and Skou (2010) suggest that reflection through "digital storytelling" can provide an important filter in developing identify and communicating emotional awareness.

It is clear that there are important design decisions around functionality and expectations for sharing and privacy that were lower than expected but they summed up the study experience. I didn't feel supported by my tutor and struggled to know where I had gone wrong but was too afraid to ask". Event type is "study experience", and emotion type is "anxious"

will impact on the experiences of the platform. Students may worry that they will be "judged" based on their journey or that they should avoid difficult topics related to individuals who may then see this journey (Fig. 10).

In response our approach is to focus on giving students control of their journey and provide features for sharing with specific named individuals (e.g. educators, mentors or support staff). Having said this, there is flexibility in the design to support other approaches, such as sharing with peers.

\section{Limitations}

This paper describes our design of Our Journey and an initial pilot trial. While there is evidence that the concept and platform have broad applicability, the trial focuses on a particular group of students studying at a distance learning institution. The data from this trial provides insights into how it could be used to better understand mental health in study but is not at a breadth and scale from which conclusions can be drawn about student mental health in general.

Our design means that Our Journey can be used alongside study, creating an ongoing activity and representation of the journey. However, in this trial the journeys were created retrospectively, resulting in the recalling of events sometime after they occurred. This presents potential for recall bias.

The design of Our Journey in terms of the types of emotion and event that are available to students to choose is likely to influence their representation of their journey. Our survey asked participants to identify emotions and event types that they felt were missing and these have informed changes to the range of emotions that can be represented in the platform.

\section{Next Steps}

We are expanding the piloting and use of this platform in different scenarios and collaborating with other institutions to widen use. These pilots allow exploration of ways in which Our Journey can be embedded in curricula and how it can be 
used to support particular areas of activity, such as mentoring or personal development planning.

Through these subsequent pilots, which will benefit from the improved functionality described above, we can develop further processes for analysing journeys in relation to other forms of analytics, and further insights into mental health and wellbeing in study. It is apparent that Our Journey can also be used to develop richer understanding in other areas and can be embedded into activities such as personal development planning.

\section{Conclusion}

Our Journey has been developed with the participation of students and in response to recognised challenges in making student mental health and wellbeing more visible to staff and institutions, while prompting student reflection. The design process and trial reported here provides encouraging evidence that this approach has merit and could be widely applicable. At the same time, there are interesting aspects of the design for refinement and further exploration, such as the approach to privacy and sharing. Furthermore, there is a need to identify effective practices in embedding this activity into student experiences, which will occur through upcoming pilots. The platform is available for anyone to explore at: https://ourjourney.ac.uk/.

Acknowledgements We would like to thank all the students, staff, and organisations who have participated in the design process.

Funding The research and development reported in this paper was supported by a grant from Jisc (jisc.ac.uk/). The initial design of Our Journey was supported by a Higher Education Innovation Fund (HEIF) Stimulating Knowledge Exchange grant.

\section{Declarations}

Conflict of Interest The authors declare no competing interests.

Open Access This article is licensed under a Creative Commons Attribution 4.0 International License, which permits use, sharing, adaptation, distribution and reproduction in any medium or format, as long as you give appropriate credit to the original author(s) and the source, provide a link to the Creative Commons licence, and indicate if changes were made. The images or other third party material in this article are included in the article's Creative Commons licence, unless indicated otherwise in a credit line to the material. If material is not included in the article's Creative Commons licence and your intended use is not permitted by statutory regulation or exceeds the permitted use, you will need to obtain permission directly from the copyright holder. To view a copy of this licence, visit http://creativecommons.org/licenses/by/4.0/.

\section{References}

Auerbach, R. P., Alonso, J., Axinn, W. G., Cuijpers, P., Ebert, D. D., Green, J. G., Hwang, I., Kessler, R. C., Liu, H., Mortier, P., Nock, M. K., Pinder-Amaker, S., Sampson, N. A., Aguilar-Gaxiola, S., Al-Hamzawi, A., Andrade, L. H., Benjet, C., Caldas-de-Almeida, J. M., Demyttenaere, K., Bruffaerts, R. (2016). Mental disorders among college students in the World Health Organization World Mental Health Surveys. Psychological Medicine, 46(14), 2955-2970.

Baker, R., \& Ocumpaugh, J. (2015). Interaction-based affect detection in educational software. In R. Calvo et al. (eds.) The Oxford handbook of affective computing, (pp. 233-245). Oxford University Press.

Barr, B. (2014). Identifying and addressing the mental health needs of online students in higher education. Online Journal of Distance Learning Administration, 17(2).

Böke, B. N., Mills, D. J., Mettler, J., \& Heath, N. L. (2019). Stress and coping patterns of university students. Journal of College Student Development, 60(1), 85-103.

Boyle, A., Maguire, S., Martin, A., Milsom, C., Nash, R., Rawlinson, S., Turner, A., Wurthmann, S., \& Conchie, S. (2007). Fieldwork is good: The student perception and the affective domain. Journal of Geography in Higher Education, 31(2), 299-317.

Coughlan, T., Lister, K., \& Freear, N. (2019). Our Journey: Designing and utilising a tool to support students to represent their study journeys. Proceedings of the 13th Annual International Technology, Education and Development Conference (INTED) 20193140-3147.

Cuijpers, P., Cristea, I. A., Ebert, D. D., Koot, H. M., Auerbach, R. P., Bruffaerts, R., \& Kessler, R. C. (2016). Psychological treatment of depression in college students: A meta analysis. Depression and Anxiety, 33(5), 400-414.

Davies, E. B., Morriss, R., \& Glazebrook, C. (2014). Computerdelivered and web-based interventions to improve depression, anxiety, and psychological well-being of university students: A systematic review and meta-analysis. Journal of Medical Internet Research, 16(5), e130.

Gulliver, A., Farrer, L., Bennett, K., \& Griffiths, K. M. (2019). University staff mental health literacy, stigma and their experience of students with mental health problems. Journal of Further and Higher Education, 43(3), 434-442.

Hartrey, L., Denieffe, S., \& Wells, J. S. (2017). A systematic review of barriers and supports to the participation of students with mental health difficulties in higher education. Mental Health \& Prevention, 6, 26-43.

Hawkes, J. (2019). A quick reference guide to mental health on university campus: A brief rhetorical analysis of fear. Disability \& Society, 34(1), 162-168.

Henriksen, D., Cain, W., \& Mishra, P. (2018). Everyone designs: Learner autonomy through creative, reflective, and iterative practice mindsets. Journal of Formative Design in Learning, 2(2), 69-81. https://doi.org/10.1007/s41686-018-0024-6

Hill, J., Healey, R. L., West, H., \& Déry, C. (2019). Pedagogic partnership in higher education: Encountering emotion in learning and enhancing student wellbeing. Journal of Geography in Higher Education. (early access).

Jamissen, G., \& Skou, G. (2010). Poetic reflection through digital storytelling-A methodology to foster professional health worker identity in students. Seminar.net 6(2).

Lipson, S. K., Lattie, E. G., \& Eisenberg, D. (2018). Increased rates of mental health service utilization by U.S. college students: 10-Year population-level trends (2007-2017). Psychiatric Services, $70(1), 60-63$. 
MacCann, C., Jiang, Y., Brown, L. E., Double, K. S., Bucich, M., \& Minbashian, A. (2020). Emotional intelligence predicts academic performance: A meta-analysis. Psychological Bulletin, 146(2), $150-186$

Markoulakis, R., \& Kirsh, B. (2013). Difficulties for university students with mental health problems: A critical interpretive synthesis. The Review of Higher Education, 37(1), 77-100.

Martin, J. M. (2010). Stigma and student mental health in higher education. Higher Education Research \& Development, 29(3), 259-274

Open University (2020). Facts and Figures 2019/20. Retrieved from: https://www.open.ac.uk/about/main/sites/www.open.ac.uk.about. main/files/files/Facts-and-Figures-2019-20.pdf

O'Regan, K. (2003). Emotion and e-learning. Journal of Asynchronous Learning Networks, 7(3), 78-92.

Petrovica, S., Anohina-Naumeca, A., \& Ekenel, H. K. (2017). Emotion recognition in affective tutoring systems: Collection of groundtruth data. Procedia Computer Science, 104, 437-444.

Picard, R. W. (2003). Affective computing: Challenges. International Journal of Human-Computer Studies, 59(1-2), 55-64.

Ryan, M. (2012). Conceptualising and teaching discursive and performative reflection in higher education. Studies in Continuing Education, 34(2), 207-223.

Smyth, J. M., Hockemeyer, J. R., Heron, K. E., Wonderlich, S. A., \& Pennebaker, J. W. (2008). Prevalence, type, disclosure, and severity of adverse life events in college students. Journal of American College Health, 57(1), 69-76.
Spalding, E., \& Wilson, A. (2002). Demystifying reflection: A study of pedagogical strategies that encourage reflective journal writing. Teachers College Record, 104(7), 1393-1421.

Stork, M. (2020). Supporting twenty-first century competencies using robots and digital storytelling. Journal of Formative Design in Learning, 4(1), 43-50. https://doi.org/10.1007/s41686-019-00039-w

Tinklin, T., Riddell, S., \& Wilson, A. (2005). Support for students with mental health difficulties in higher education: The students' perspective. British Journal of Guidance \& Counselling, 33(4), 495-512.

Veine, S., Kalvig Anderson, M., Haugland Andersen, N., Espenes, T. C., Søyland, T. B., Wallin, P., \& Reams, J. (2020). Reflection as a core student learning activity in higher education - Insights from nearly two decades of academic development, International Journal for Academic Development, 25(2), 147-161.

Wallin, P., \& Adawi, T. (2018). The reflective diary as a method for the formative assessment of self-regulated learning. European Journal of Engineering Education, 43(4), 507-521.

Wei, M. H. (2007). University policy and procedural responses to students at risk of suicide. Journal of College \& University Law, 35.

Publisher's Note Springer Nature remains neutral with regard to jurisdictional claims in published maps and institutional affiliations. 